\title{
A PARAMETRIC STUDY OF MULTY- STOREY R/C BUILDINGS WITH HORIZONTAL IRREGULARITY
}

\author{
Himanshu Gaur ${ }^{1}$, R.K Goliya ${ }^{2}$, Krishna Murari ${ }^{3}$, Dr. A. K Mullick ${ }^{4}$ \\ ${ }^{1}$ Assist. Prof., Const. Tech. \& Management Dept., Dire Dawa University, Dire Dawa, Ethiopia \\ ${ }^{2}$ Assistant Professor, Civil Engineering Department, JUET, Guna, India \\ ${ }^{3}$ Assistant Professor, Civil Engineering Department, JUET, Guna, India \\ ${ }^{4}$ Visiting Faculty, Civil Engineering Department, JUET, Guna, India
}

\begin{abstract}
In designing the multistoried buildings, irregularity in structures is inevitable due to the functional requirement of the buildings. In the present paper horizontally irregular buildings are analyzed for their stability. Multistory horizontally irregular buildings, as described in IS 1893:2002, were modeled in program STAAD.pro. Irregular plan like $L$ - shape, H - shape and U- shape are considered for study. Each building is raised 20 storeys high. Assessment is done on the basis of lateral length ratio for each shape. Buildings are analyzed for Dead loads, Live loads and Wind loads are set as described in IS 875 part 1, 2 and 3 respectively. Earthquake load is set as per IS 1893: 2002. Combinations of loads are taken as per the relevant Indian Standard codes. Parameters like internal forces and roof displacement are used for the assessment. Results are plotted for internal forces of critical members and roof displacements versus lateral length ratios for different shapes.
\end{abstract}

Keywords: Horizontal Irregularity, Earthquake load, Wind load, Multistory R/C buildings. $* * *$

\section{INTRODUCTION}

In most developing economies around the world, the cities are growing at faster rates. One of the common features of this growth is the need to grow vertical, as the horizontal expansions have reached a degree of saturation. With more and more high-rise buildings, the lateral loads affect the buildings in more than one way. The direct action of lateral loads (Earthquake and Wind) causes heavy moments and forces at base of the building. With asymmetric plan, further complexity is introduced as torsional forces become predominant.

Recent reports on post-earthquake surveys have shown that many buildings have collapsed due to torsional effects in buildings with irregular plan. IS: 1893-2002 Indian Standard Criteria for Earthquake Resistant Design of Structures (Part-1, General considerations and building) also defines different categories of irregularities in building plan and elevation. In case of horizontally asymmetric buildings, the asymmetry is measured by the presence of torsion in the building. Asymmetric horizontal buildings possess separate centre of mass and centre of stiffness of the storey. Eccentricity between the two centers causes the torsion in the building which in turn is responsible for successive damage. If building is symmetrical about the two axes the centre of lateral stiffness of the storey and centre of mass coincides on each other. The earthquake forces acts through the centre of mass of the floor diaphragm and is resisted by the building at the centre of rigidity by its stiffening members.

The present study is an attempt to parametrically studying the effects of building plan irregularities on different internal forces and top storey displacements. Three different shapes of buildings were considered with different length ratios.

\section{LITERATURE REVIEW}

S.K. Jain et. al. have emphasis on architectural (functional requirement) design of building in the present scenario in India. According to them there are so many building that have soft first storey. Due to the functional requirement of the first storey like parking facility, economic functionality etc. buildings are designed with no considerations towards the stiffness of first storeys. There is soft storey due to the absence of brick infill walls which has been removed for the functional requirement. Absence of wall reduces stiffness of this first storey leading it to soft storey. They have suggested that use of Central Concrete Core method or providing additional strength to the columns are the two ways that can eliminate the effect of this soft storey.

F. Gultan Gulay et. al. have presented the work on torsional unbalanced irregular structures for the verification of code specific design requirement of irregular structures of Turkish Earthquake Code, TEC'97. Irregular structures face torsional forces in them due to the different stiffness distribution in 
building diaphragm. Due to the architectural requirement of the building it is inevitable to introduce irregularity in the building and designers need to design the building to resist these severe twisting forces.

\section{PROBLEM DEFINITION}

In the present paper horizontally irregular buildings are considered for the study. Each building modeled in the program STAAD.pro is twenty storeys high. Bays are of 4 meters length each whereas roof height is set as 3 meters high each. Material considered is of reinforce concrete.

In Figure 1 typical floor plans are shown for different shapes of horizontal irregular buildings. For more elaboration take the example of $\mathrm{L}$ shape plans. In the figure, this particular floor plan is for lateral length ratio (L1/L2) 0.43 .

In the same way this ratio of lateral length is varying from zero to 4 for all L shape plans.

In the same way other horizontal irregular plans are modeled with varying lateral length ratio for finding the most stable structure among them.

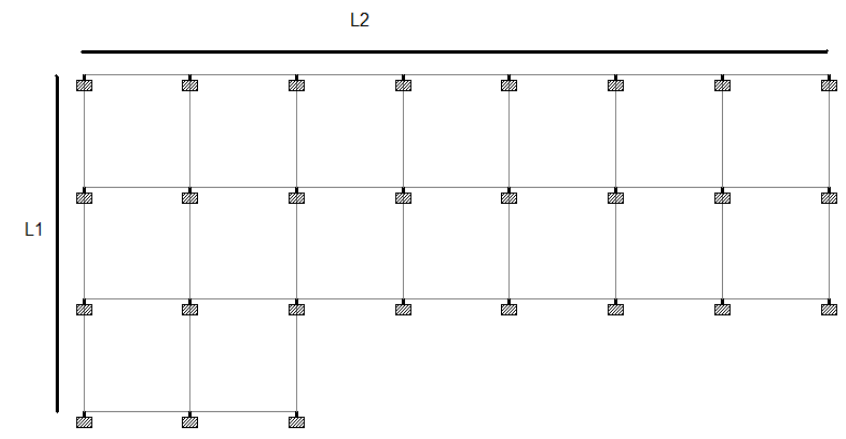

(a)

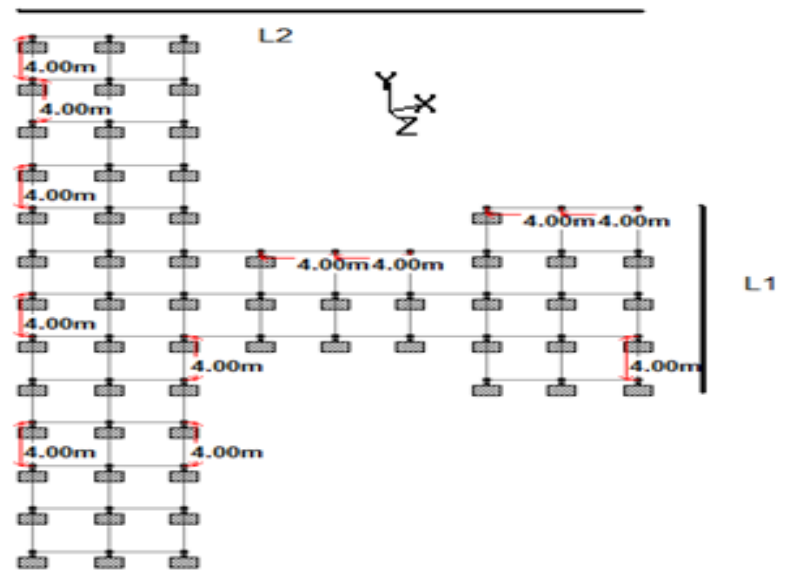

(b)

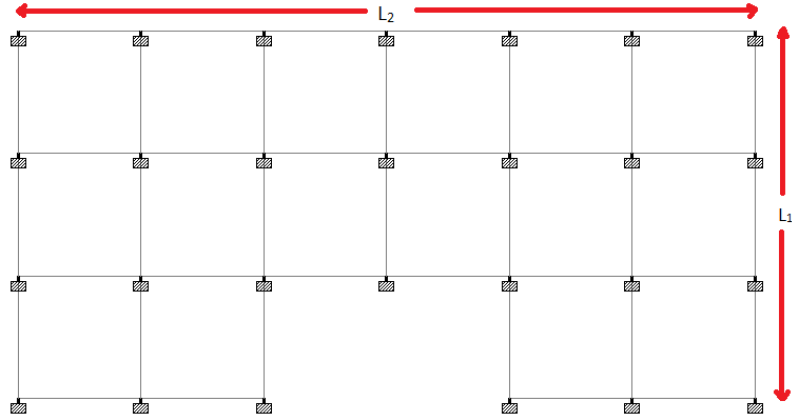

(c)

Fig 1 Typical floor plans (a) L-shape (b) H-shape (c) U-shape

\section{RESULTS AND DISCUSSION}

For finding the most stable structure among them all, graphs are plotted between the parameters used versus lateral length ration for different stapes. Results are shown here. While observing the response of L shape buildings, Figure-2 shows the graph of variation of bending moment, maximum of $\mathrm{Mx}$ or $\mathrm{Mz}$, for a particular column among all columns of ground storey, versus lateral length ratio. Again Figure -3 and 4 shows the graph of variation of floor displacement in $\mathrm{X}$ and $\mathrm{Z}$ direction respectively of top storey for the node shown in insert

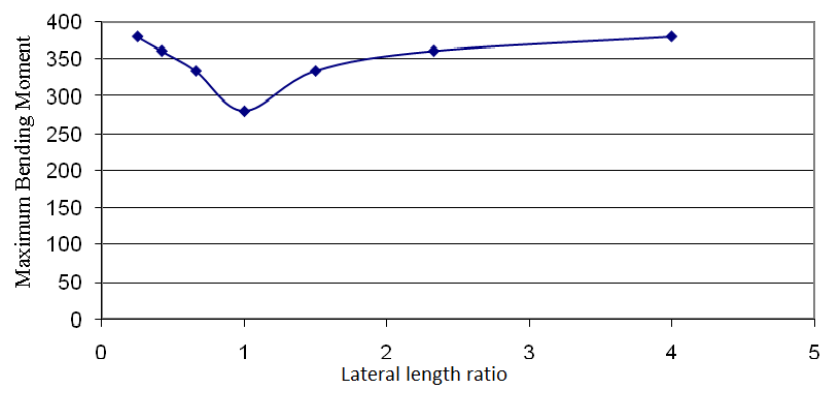

Fig 2 Variation of bending moment, for the maximum value of it (either $\mathrm{M}_{\mathrm{x}}$ of $\mathrm{M}_{\mathrm{z}}$ ) among all columns of ground storey for $\mathrm{L}$ shape plan buildings

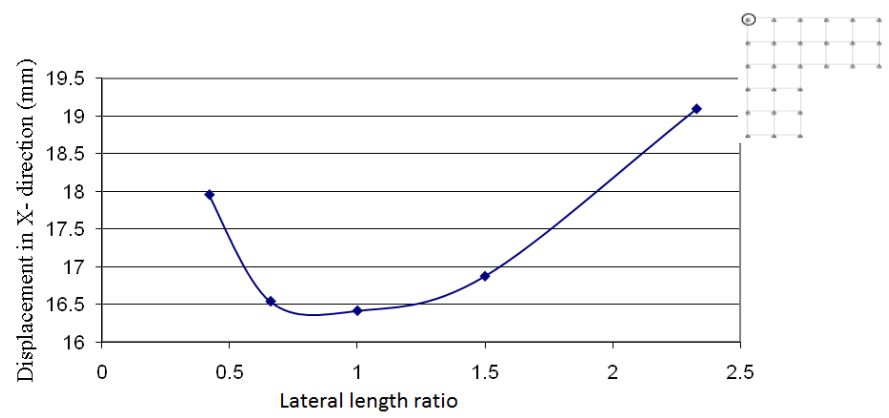

Fig 3 Variation of top storey node, shown, of L-shaped plan buildings 


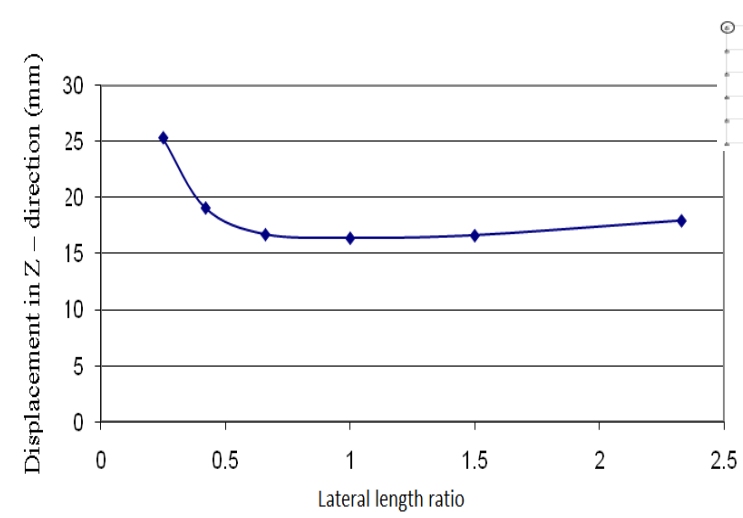

Fig 4 Variation of top storey node, shown, of L-shaped plan buildings

For $\mathrm{H}$ shape plans, variation of bending moment for a particular column of ground storey versus lateral length ratio is drawn. Figure -5, 6 and 7 shows the typical variation of Zdirectional bending moment for the mentioned column.

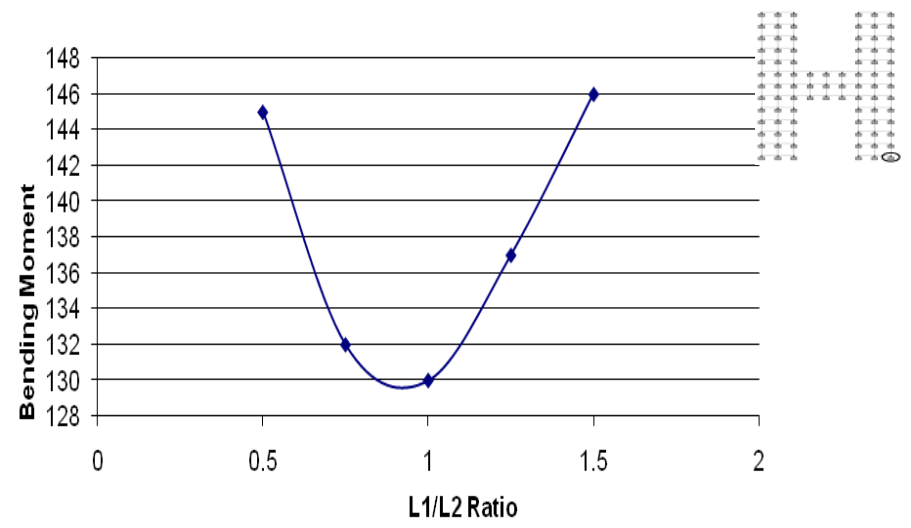

Fig 5 Variation in Bending Moment for the column shown, in the direction parallel to web

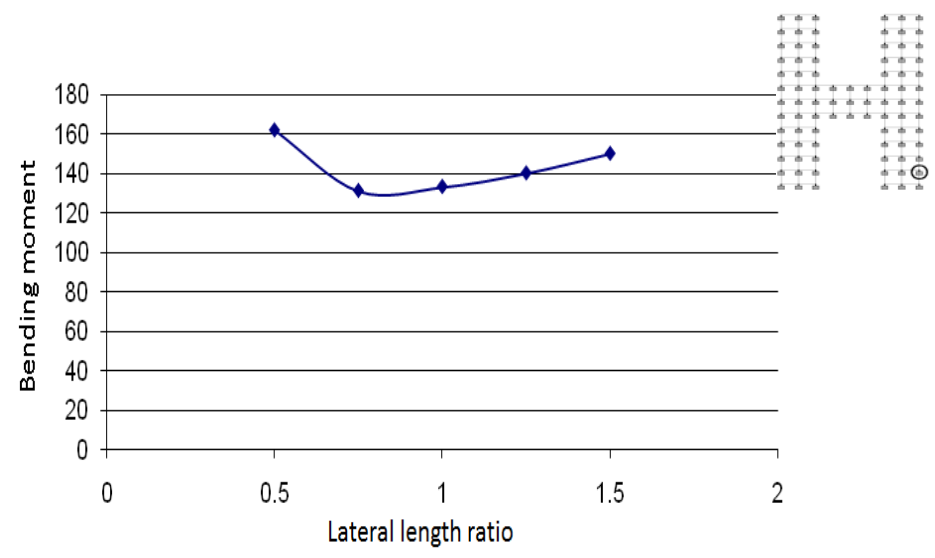

Fig 6 Variation in Bending Moment for the column shown, in the direction parallel to web

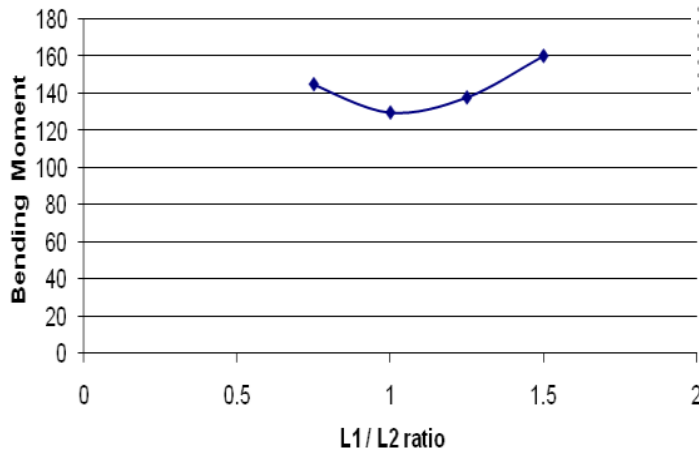

Fig 7 Variation in Bending Moment for the column shown, in the direction parallel to web

Following graphs shows the response of $U$ shape plan buildings. These graphs are drawn for the bending moment as well as resultant of lateral displacements of top storey nodes.

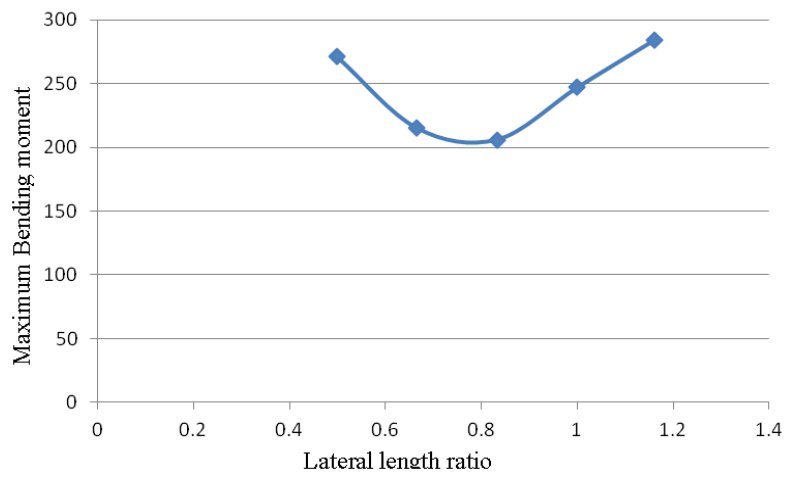

Fig 8 Variation of bending moment, for the maximum value of it (either $\mathrm{M}_{\mathrm{x}}$ of $\mathrm{M}_{\mathrm{z}}$ ) among all columns of ground storey for $\mathrm{U}$ shape plan buildings

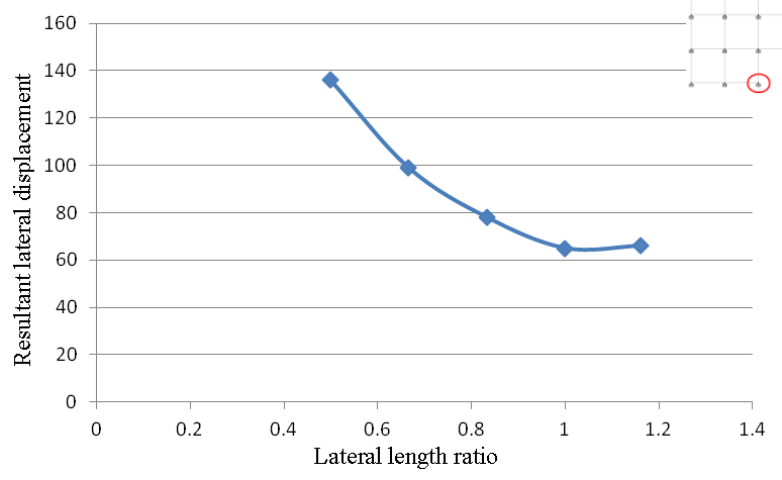

Fig 9 Variation of resultant lateral displacement for the mentioned node of top storey 


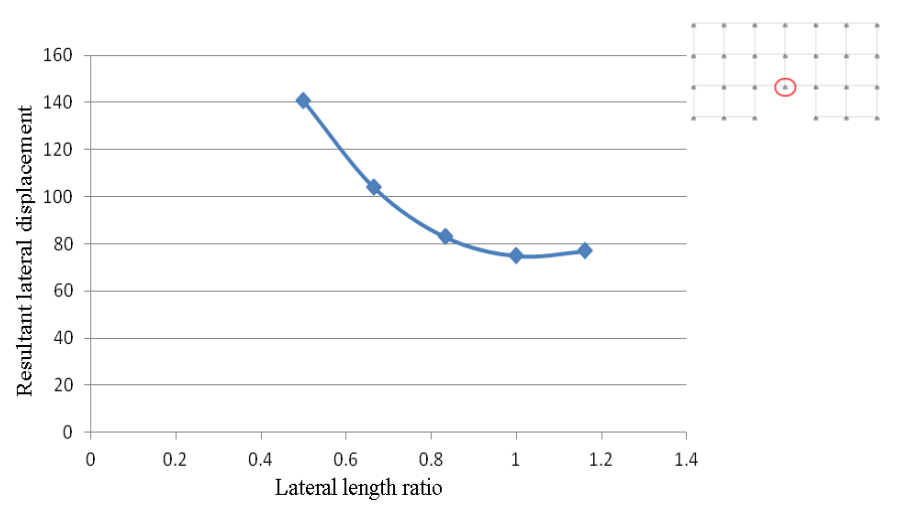

Fig 10 Variation of resultant lateral displacement for the mentioned node of top storey

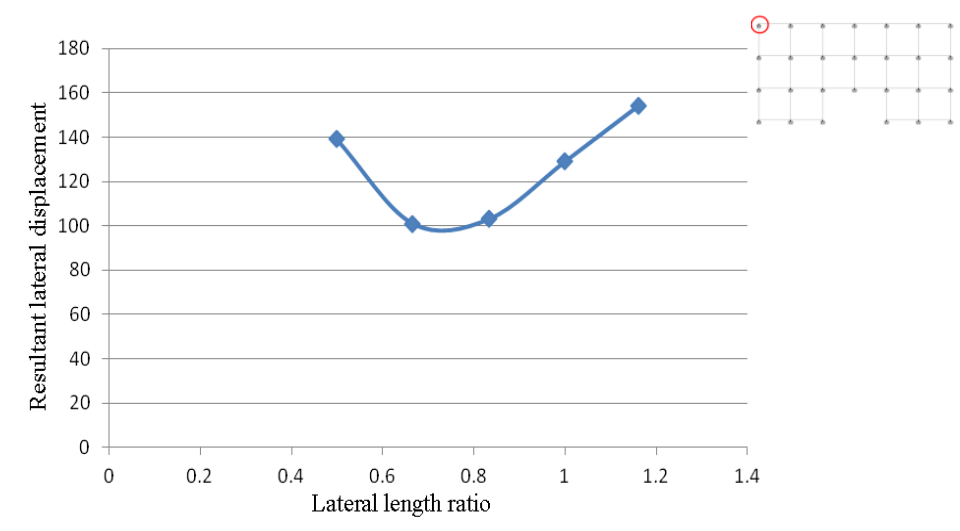

Fig 11 Variation of resultant lateral displacement for the mentioned node of top storey

\section{CONCLUSIONS}

In STAAD.pro $\mathrm{X}$ and $\mathrm{Z}$ are respectively two global horizontal directions and $\mathrm{Y}$ is considered as vertical. Figure- 2 shows the graph for L shape plans. It is drawn between the maximum values of bending moment either $\mathrm{Mx}$ or $\mathrm{Mz}$, among all columns of ground storey versus lateral length ratio. It is clear that minimum value is obtained for the lateral length ratio 1.

Again Figure-3 and 4 shows the graph lateral displacement of nodes of top storey of the $\mathrm{L}$ shape plans. Minimum value of displacement is again for lateral length ratio 1 . Together with the results of variation of bending moment and top storey displacements, it can be stated that lateral length ratio 1 is the most stable structure among all for L shape plans.

While assessing the stability of $\mathrm{H}$ shape structure, variation in moment in $\mathrm{Z}$ direction for the particular column of ground storey is shown in figure 5, 6 and 7 . It can be observed that plan with $\mathrm{L} 1 / \mathrm{L} 2=1$ has the least value of moment among rest of the plans.

This least value is assigning this plan as the most stable structure among all rest of the $\mathrm{H}$ shape plans.
Now for $U$ shape plans, Figure 8 shows the variation of bending moment, maximum of $\mathrm{Mx}$ or $\mathrm{Mz}$ for any particular column of ground storey. It can be observed that for lateral length ratio 0.833 , this value is coming minimum.

Now observing the response of variation of resultant of lateral displacement for the top storey nodes, graphs in figure 9 and 10 are alike, which are giving the least value resultant displacement for lateral length ratio 1 .

Variation of this resultant displacement for the top storey node as mentioned in Figure 11 is giving the least value for the lateral length ratio 0.666 .

Hence for $U$ shape plans, results are not stating any particular plan as the most stable among all of them. By observing graph of Figure 9 and 10, it can be stated that stability decrease as lateral length ratio increases above 1. Observations from Figure 8 and 11 state that lateral length ratio less than 6 is also not stable comparatively for $\mathrm{U}$ shape plan buildings.

\section{REFERENCES}

[1] Proença. J., Oliveira. Carlos S. and Almeida. J.P. (2004), "Seismic Performance Assessment of Reinforced Concrete Structures with Masonry in filled Panels", ISET Journal of Earthquake Technology, paper no. 449, Volume 41, No. 2 - 4, No.3.

[2] Taskin Beyza, Guler Kadir, and Altan Melike. (2004), "Evaluation of the Role of Architectural Design in Earthquake Damages of RC Buildings", Dept. of Civil Engineering, Istanbul Technical University, Maslak, Istanbul, 34469, Turkey.

[3] Gulay. F. Gultan and Calim Gokhan. "A Comparative Study of Torsionally Unbalanced Multi - Storey Structures under Seismic Loading.” (2001), Istanbul Technical University, Civil Engineering Department, 80626 Maslak, Istanbul, Turkey.

[4] Jain. K., Murti C. V. and Arlekar Jaswant N. (2000), "Seismic Response of RC Frame Building with Soft First Storey", Indian Institute of Technology, Kanpur, India.

[5] BIS (2002). "IS 1893 (Part 1)-2002: Indian Standard Criteria for Earthquake Resistant Design of Structures, Part 1 - General Provisions and Buildings (Fifth Revision)", Bureau of Indian Standards, New Delhi.

[6] BIS (1987). "IS 875 (Part 1) - 1987 Indian standard code of practice for design loads (other than earthquake) for buildings and structures", Bureau of Indian Standard, New Delhi.

[7] BIS (1987). "IS 875 (Part 2) - 1987 "Indian standard Code of practice for design load (other than earthquake) for buildings and structures", Bureau of Indian Standard, New Delhi.

[8] BIS (1987). "IS 875 (Part 3) - 1987 "Indian Standard code of practice for design loads (other than 
earthquake) for buildings and structures", Bureau of Indian Standard, New Delhi.

[9] BIS (1987). "IS 875 (Part 5) - 1987 "Indian Standard code of practice for design loads ( other than earthquake) for buildings and structures", Bureau of Indian Standard, New Delhi

[10] BIS (2000). "IS: 456 - 2000 "Standard plan and reinforced concrete- code of practice", Bureau of Indian Standard, New Delhi.

[11] BIS (1972). "SP 6 (6) - 1972, "Handbook for Structural Engineers", Bureau of Indian Standard, New Delhi.

[12] BIS (1993). "IS 13920: 1993 "Ductile Detailing of Reinforced Concrete Structures Subjected To Seismic Forces - Code Of Practice", Bureau of Indian Standard, New Delhi.

\section{BIOGRAPHIES}

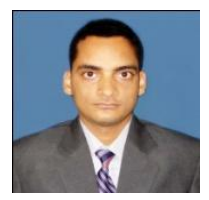

Himanshu Gaur has completed his M.Tech in Construction Management from JUET, Guna in 2009. He is currently working as Assistant Professor in Dire Dawa University, Dire Dawa, Ethiopia. His research interest is in Structural Engineering, Earthquake Engineering, FEA etc.

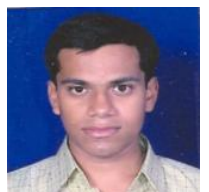

Mr. Ravindra Kumar Goliya has completed his M.Tech in Structural Dynamics from IIT Roorkee. Currently he is working as Assistant Professor in JUET, Guna and also pursuing his research work in Wind Energy. He is also experienced in designing High Rise Buildings and Underground Metro Stations.

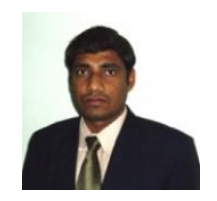

Mr. Krishna Murari has done M.Tech. from Institute of Technology B.H.U, Varanasi in Structural engineering in 2005. He is currently pursuing his research work and working as Assistant Professor in the Department of Civil Engineering, JUET, Guna. His area of interest is in Problem and Prospects in Earthquake engineering.

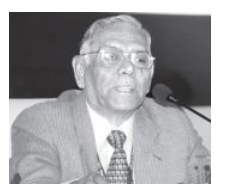

Dr. Ajoy K. Mullick is Former Director General of NCB, New Delhi, India. He is also among eminent persons of JAYPEE Group and visiting faculty of JUET, Guna. 